\title{
Skin prick test reactivity to aeroallergens in Jordanian allergic rhinitis patients
}

S. Aburuz, ${ }^{1,2}$ N. Bulatova'and M. Tawalbeh ${ }^{3}$

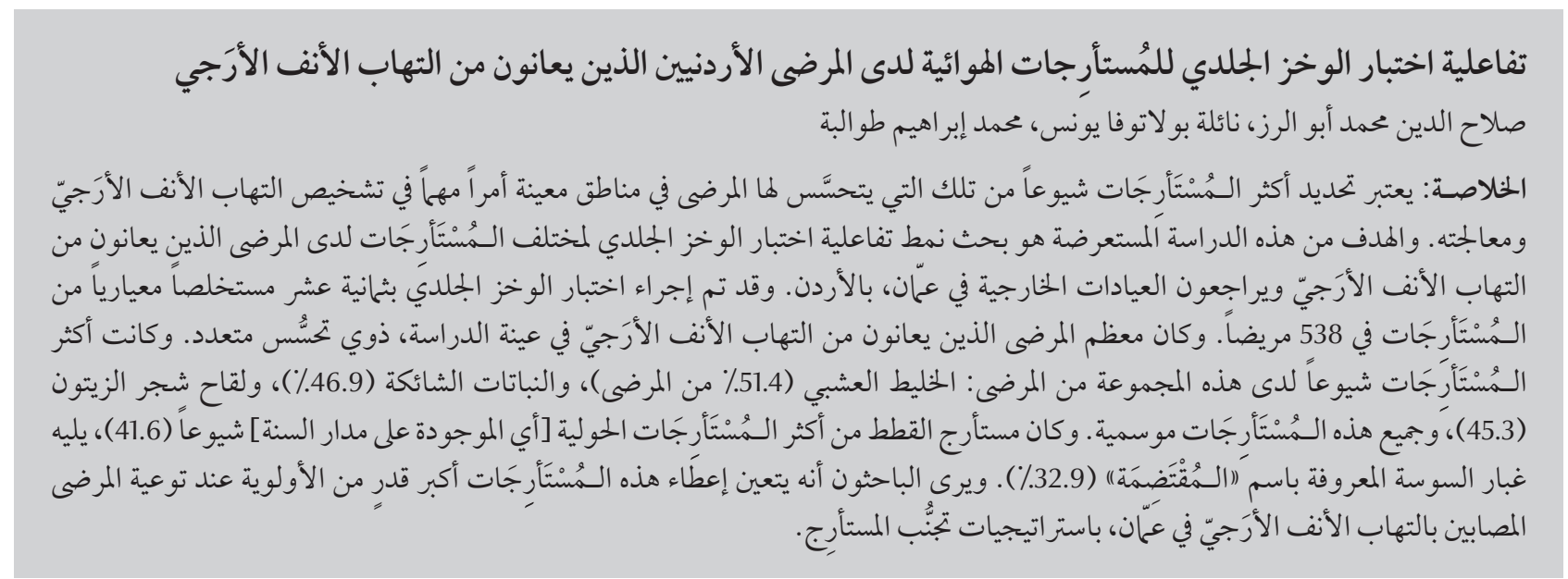

ABSTRACT Identification of the most common aeroallergens to which patients are sensitized in a specific area is important in the diagnosis and treatment of allergic rhinitis. The aim of this cross-sectional study was to investigate the pattern of skin prick test reactivity to various aeroallergens among allergic rhinitis patients attending outpatient clinics in Amman, Jordan. Skin prick test with 18 standardized allergen extracts was performed on 538 patients. Most allergic rhinitis patients in the study sample had polysensitization. Grasses mix (51.4\% of patients), thistleweed $(46.9 \%)$ and olive tree $(45.3 \%)$ pollens were the most common allergens in this group of patients (all seasonal). Cat allergen was the most common perennial allergen (41.6\%), followed by dust mite Dermatophagoides pteronyssinus (32.9\%). These allergens should be given the highest priority when educating allergic rhinitis patients in Amman regarding allergen avoidance strategies.

Réactivité aux tests cutanés d'aéroallergènes chez des patients jordaniens atteints de rhinite allergique

RÉSUMÉ L'identification des aéroallergènes auxquels les patients sont les plus fréquemment sensibilisés dans une zone particulière est importante pour le diagnostic et le traitement de la rhinite allergique. La présente étude transversale visait à rechercher le modèle de réactivité aux tests cutanés de différents aéroallergènes chez des patients atteints de rhinite allergique se présentant dans des centres de consultations externes à Amman (Jordanie). Un test cutané composé de 18 extraits d'allergènes normalisés a été réalisé sur 538 patients. La plupart des patients atteints de rhinite allergique dans l'échantillon de l'étude souffraient de polysensibilisation. Les pollens de graminées (51,4 \% des patients), de chardon (46,9\%) et d'olivier (45,3\%) étaient les allergènes (tous saisonniers) les plus fréquents dans ce groupe de patients. Les phanères de chat étaient l'allergène non saisonnier le plus répandu (41,6 \%), suivis par les acariens (ou dermatophagoïdes pteronyssinus, 32,9 \%). Ces allergènes devraient être placés en tête de liste des priorités lors de l'information des patients souffrant de rhinite allergique à Amman au sujet des stratégies d'évitement.

'Department of Clinical Pharmacy, Faculty of Pharmacy, University of Jordan, Amman, Jordan (Correspondence to S. Aburuz: aburuz@ju.edu.jo; aburuz@yahoo.com).

${ }^{2}$ Department of Pharmaceutical Care; ${ }^{3}$ Department of Ear, Nose and Throat, Faculty of Medicine, University of Jordan Hospital, Amman, Jordan. Received: 23/08/09; accepted: 31/12/09 


\section{Introduction}

Allergic rhinitis is one of the most common chronic conditions, affecting $10 \%$ to $30 \%$ of adults and up to $40 \%$ of children $[1,2]$. There is evidence of a progressive increase in the prevalence of allergic rhinitis in recent decades $[3,4]$. Sometimes mistakenly viewed as a trivial disease, symptoms of allergic rhinitis may significantly impact a patient's quality of life by causing fatigue, headache, cognitive impairment, affecting psychological well-being and other systemic symptoms $[5,6]$. Allergen avoidance should be considered as a first-line intervention in the management of allergic rhinitis as, even when not completely effective, it may reduce the need for additional treatment [7].

Sensitization to aeroallergens is the most important factor causing symptoms in allergic rhinitis [7]. Many studies have shown that the distribution and pattern of aeroallergens is significantly different from one country to another [8]. Identification of the most common aeroallergens to which the patients are sensitized has an important role in the diagnosis and treatment of allergic rhinitis. Selecting the most appropriate panel of allergen extracts for diagnostic testing and finding the best formulation of allergen immunotherapy depends on information about the most important aeroallergens in a specific area. Likewise, allergen avoidance cannot be properly achieved without identifying the allergens that are associated with allergic rhinitis for every patient.

The aim of this study was to investigate the pattern of skin prick test reactivity to various aeroallergens among allergic rhinitis patients in Jordan. To date, no such investigation has been carried out in Jordan, which is a small country in the Eastern Mediterranean with a population of over 5 million. Although there are no official statistics on the prevalence of allergic rhinitis or data regarding the most important aeroallergens, the disease is widespread in Jordan, with estimates of at least $15 \%-20 \%$ of Jordanians being affected [9].

\section{Methods}

\section{Study population and design}

A cross-sectional study was conducted at the University of Jordan hospital, Amman,Jordan, which is the largest hospital in Jordan serving annually more than 0.5 million patients. The sample included adults aged 18 years or over who were diagnosed with allergic rhinitis and were attending the hospital ear, nose, and throat outpatient clinics. The clinics serve more than 5000 patients annually from all age groups and suffering from a variety of ear nose and throat diseases. For our study, all patients aged $>18$ years diagnosed with allergic rhinitis and attending during the period January to June 2006 and January to June 2007, months during which the common regional plant species are expected to pollinate [9], were selected. Patients were excluded from the study if they had any contraindications to the skin prick test $[10,11]$.

The study was approved by the institutional review board at the University of Jordan hospital and all patients provided informed consent to participate in the study. The diagnosis of allergic rhinitis was confirmed using the score for allergic rhinitis (SFAR) [12] and clinical examination.

During the baseline visit demographic data (age, sex, marital status, education), clinical history (presence of asthma, eczema, sinusitis or family history of allergic rhinitis) and smoking status (current smoker, passive smoker, never smoked or ex-smoker) were obtained. Patients were asked to stop their antihistamine treatment and to come back to the clinic 1 week later for skin prick testing.

\section{ARIA classification}

On the basis of the Allergic Rhinitis and its Impact on Asthma (ARIA) study guidelines [13], patients whose duration of allergic symptoms was $<4$ days per week or 4 weeks per year were classified as cases of intermittent allergic rhinitis and the remainder were classified as cases of persistent allergic rhinitis.

\section{Skin prick testing}

Skin prick testing with 18 standardized allergen extracts from a commercial test kit (Stallergenes) was performed on all patients in accordance with published guidelines [14]. As some of the standardized allergen extracts were mixtures; the total number of allergens tested was approximately 50 . In general, mites, moulds and animals are considered as perennial allergens, whereas grasses, trees, cereals and weeds are considered as seasonal allergens. Allergens used in this study were chosen according to the common regional plant species [9] and other possible allergens were identified from consulting ear, nose and throat specialists. In order to ensure uniformity, the tests were performed by a single trained and experienced individual.

Histamine hydrochloride (10 mg/ $\mathrm{mL}$ ) and glycerol saline were used as positive and negative controls, respectively. The skin prick test was performed on healthy skin on the volar surface of the forearm. The test sites were placed 20-30 $\mathrm{mm}$ apart approximately $5 \mathrm{~cm}$ below the elbow and $5 \mathrm{~cm}$ above the wrist. A drop from each extract was applied to the skin (10 extracts on each arm) and then the skin was pricked through each drop using a sterile lancet (Stallerpoint, Stallergenes). The order of skin prick testing was first histamine followed by negative control then allergen extracts. The size of the weal after 20 minutes was determined by measuring the mean of the longest diameter and the diameter perpendicular to it.

\section{Interpretation of skin prick tests results}

According to the test kit manufacturer's instructions, the test is valid if the weal diameter of the positive control is $\geq 4$ 
$\mathrm{mm}$ and the weal diameter of the negative control is $\leq 3 \mathrm{~mm}$. The reaction is regarded as positive if it satisfies the following conditions: the weal diameter is larger than the negative control and is $\geq 5 \mathrm{~mm}$ or between $3-5 \mathrm{~mm}$ if it is $\geq 70 \%$ of the one obtained with the positive control. Weal diameters of $\leq 3 \mathrm{~mm}$ are regarded as negative.

\section{Statistical analysis}

Qualitative data are presented as frequencies (\%) and quantitative data as mean and standard deviation (SD). Data were analysed using SPSS, version 15. Group differences (intermittent versus persistent rhinitis and positive versus negative reactions) were studied using the chi-squared test for categorical variables or independent t-test for continuous variables. A $P$-value $<0.05$ in the 2-tailed test was considered significant. In order to take multiple comparisons into account when comparing baseline data (patients with positive sensitization versus patients with negative sensitization), only $P$-values $<0.003$ were considered significant $(0.05 / 18)$ (where 0.05 is the standard $P$-value and 18 is the number of comparisons) [15].

\section{Results}

\section{Demographic and clinical characteristics}

During the study period 554 patients with allergic rhinitis fulfilled the inclusion criteria; 16 patients refused to participate in the study and so skin prick tests were conducted on 538 patients. A further 28 patients were excluded from the final data analysis due to invalid skin prick test [histamine weal $<4 \mathrm{~mm}(1$ patient) or control weal $>3 \mathrm{~mm}(27$ patients)]. The demographic and clinical characteristics of the 510 (92.1\%) who were included in the data analysis are shown in Table 1. The mean duration of allergic rhinitis was 6 (SD 5) years. Less than half( $38.8 \%$ ) were males and $43.9 \%$ had higher education. Only $13.3 \%$ were current active smokers and
4.3\% were ex-smokers although $40.4 \%$ were exposed to passive environmental smoke.

\section{Skin prick test reactivity to aeroallergens \& characteristics of sensitized patients}

As shown in Table 2, 49 patients (9.6\%) did not react to any of the tested allergens. Of the $90.4 \%$ who demonstrated sensitization only 46 patients (9.0\%) were reactive to 1 allergen and the rest ( $81.4 \%)$ were reactive to 2 or more allergens.

Table 3 shows the number of positive sensitizations for each of the tested allergens. Grasses, olive tree and thistleweed pollens were the most common allergens (all are seasonal). Cat and dust mite (Dermatophagoides pteronyssinus) were the most common perennial allergens. Sensitization to chestnut, oak, beech tree (Fagaceae) were the least common. For each allergen patients with positive skin prick test were compared with those with negative skin prick test by age, duration of allergic rhinitis, sex and smoking habit (Table 3). Patients with positive sensitization to cat allergen and to the dust mite allergen Dermatophagoides pteronyssinus were significantly younger. Significantly more males than females were sensitized to feather mix allergen.

The distribution of positive skin test responses by allergen categories are shown in Figure 1. The most prevalent allergen category was tree pollen; 333 (65.3\%) of all patients were sensitized to at least 1 tree. The second most prevalent category was weed pollens, followed by grass pollens. Among the perennial allergens, mould was the most common; 259 (50.8\%) of patients were sensitized to at least 1 mould.

\begin{tabular}{|c|c|c|}
\hline \multirow[t]{2}{*}{ Variable } & \multicolumn{2}{|c|}{ Value } \\
\hline & Mean & SD \\
\hline Age (years) & 34.4 & 13.1 \\
\hline \multirow[t]{2}{*}{ Duration of allergic rhinitis (years) } & 6 & 5 \\
\hline & No. & $\%$ \\
\hline Sex: male & 198 & 38.8 \\
\hline Marital status: married & 267 & 52.4 \\
\hline \multicolumn{3}{|l|}{ Educational level } \\
\hline High school & 189 & 37.1 \\
\hline College & 97 & 19.0 \\
\hline University degree & 224 & 43.9 \\
\hline \multicolumn{3}{|l|}{ Classification of allergic rhinitis } \\
\hline Intermittent & 156 & 30.6 \\
\hline Persistent & 354 & 69.4 \\
\hline \multicolumn{3}{|l|}{ Clinical history } \\
\hline Positive family history of allergic rhinitis & 137 & 26.9 \\
\hline Concomitant asthma & 86 & 16.9 \\
\hline Concomitant eczema & 94 & 18.4 \\
\hline Concomitant sinusitis & 22 & 4.3 \\
\hline \multicolumn{3}{|l|}{ Smoking history } \\
\hline Current smoker & 68 & 13.3 \\
\hline Passive smoker & 206 & 40.4 \\
\hline Never smoked & 214 & 42.0 \\
\hline Ex-smoker & 22 & 4.3 \\
\hline
\end{tabular}

$S D=$ standard deviation. 


\begin{tabular}{lcc}
\hline \multicolumn{3}{c}{ Table 2 Frequency of positive skin test responses among allergic rhinitis patients } \\
\hline No. of allergens & No. of patients sensitized & $\%$ \\
0 & 49 & 9.6 \\
1 & 46 & 9.0 \\
2 & 45 & 8.8 \\
3 & 45 & 8.8 \\
4 & 40 & 7.8 \\
5 & 61 & 12.0 \\
6 & 54 & 10.6 \\
7 & 36 & 7.1 \\
8 & 36 & 7.1 \\
9 & 25 & 4.9 \\
10 & 33 & 6.5 \\
11 & 19 & 3.7 \\
12 & 11 & 2.2 \\
13 & 8 & 1.6 \\
14 & 2 & 0.4 \\
Total & 510 & 100.0 \\
\hline
\end{tabular}

\section{Association between allergen- specific sensitization and class of allergic rhinitis}

Table 4 compares the allergen-specific sensitization for the 156 patients (30.6\%) with intermittent allergic rhinitis versus 354 patients (69.4\%) with persistent allergic rhinitis. The seasonal allergens (grasses, trees and cereals pollens) were significantly associated with persistent allergic rhinitis. Patients with persistent allergic rhinitis had on average a higher number of positive allergen sensitizations.

\section{Discussion}

This study reported on skin prick test reactivity to aeroallergens among patients with allergic rhinitis in Jordan. Nearly one-tenth of patients $(9.6 \%)$ showed no positive sensitivity reactions; however, since all patients in the sample were clinically diagnosed with allergic rhinitis, they were probably sensitized to other allergens not included in our battery of tests. Since this is the first report of reactivity to common aeroallergens in Jordan, there is a high possibility that we have missed testing some important allergens.
Most study patients (81.4\%) were reactive to 2 or more allergens. Similar findings were also obtained from studies in the Islamic Republic of Iran and Kuwait, where polysensitization was found in $76 \%, 85 \%$ and $65 \%$ of patients respectively $[16,17]$. Polysensitization might be the result of genetic factors [18] or environmental factors which favour growth and vegetation of specific plant species such as grass and weeds with similar survival conditions [16]. It might also be due to cross-reactivity which reflects the presence of common allergenic epitopes in different but botanically close plant species $[16,19]$. We used a number of closely related species which may have contributed to the high rate of polysensitization.

Grasses, thistleweed and olive tree pollens were the most common allergens and all of these are seasonal. The most prevalent allergen in this study was grass pollens; $51.4 \%$ of patients were sensitized to grasses, which is a lower rate than found in similar studies in European countries but higher than in Saudi Arabia [20] and the United Arab Emirates (UAE) [21]. Thistleweed pollen was the most common allergen encountered in a study of allergic rhinitis patients in the Islamic Republic of Iran [16], where the rate of sensitization was considerably higher at $89 \%$. A very high rate of sensitization to thistleweed was also found in Kuwait, Saudi Arabia and the UAE $[17,20,21]$. All these countries are characterized by a hot and humid climate compared with the dry and moderate climate of Jordan. Olive tree pollen was the second most common sensitizing allergen (68\%) in a study from Italy [22] and it was one of the most common allergens in a study from Turkey [23], and is probably a common allergen from most countries where olives are cultivated. In contrast to the present study, olive tree pollen was not found to be an important allergen in studies from the Islamic Republic of Iran, Kuwait, Saudi Arabia and UAE $[16,17,20,21]$. This is expected as olives are not normally cultivated in these countries. Olive trees are widely cultivated all over Jordan and several Middle Eastern countries for ornamental and business purposes. We would estimate that between $20 \%-50 \%$ of households in Jordan are cultivating 10-20 olive trees each. It is well known that olive tree pollen contributes to the development and deterioration of allergic diseases [24]. Unpublished reports from Jordan estimate that at least $15 \%-20 \%$ of the population are suffering from allergic diseases. The high prevalence of olive tree pollen sensitization in our sample indicates that it is probably a major factor involved in the increasing prevalence of allergic diseases. This raises a health concern and we recommend against cultivating olive trees near residential areas.

Cat dander was the most common perennial allergen. Although only a few families in Jordan keep cats as pets in their homes, cats can be found in almost every area of Jordan. It is known that cat allergy can be a major problem even for those who do not own them [25]. Cat allergens are produced in large amounts and cat dander is airborne, sticky and found in public places even where there 


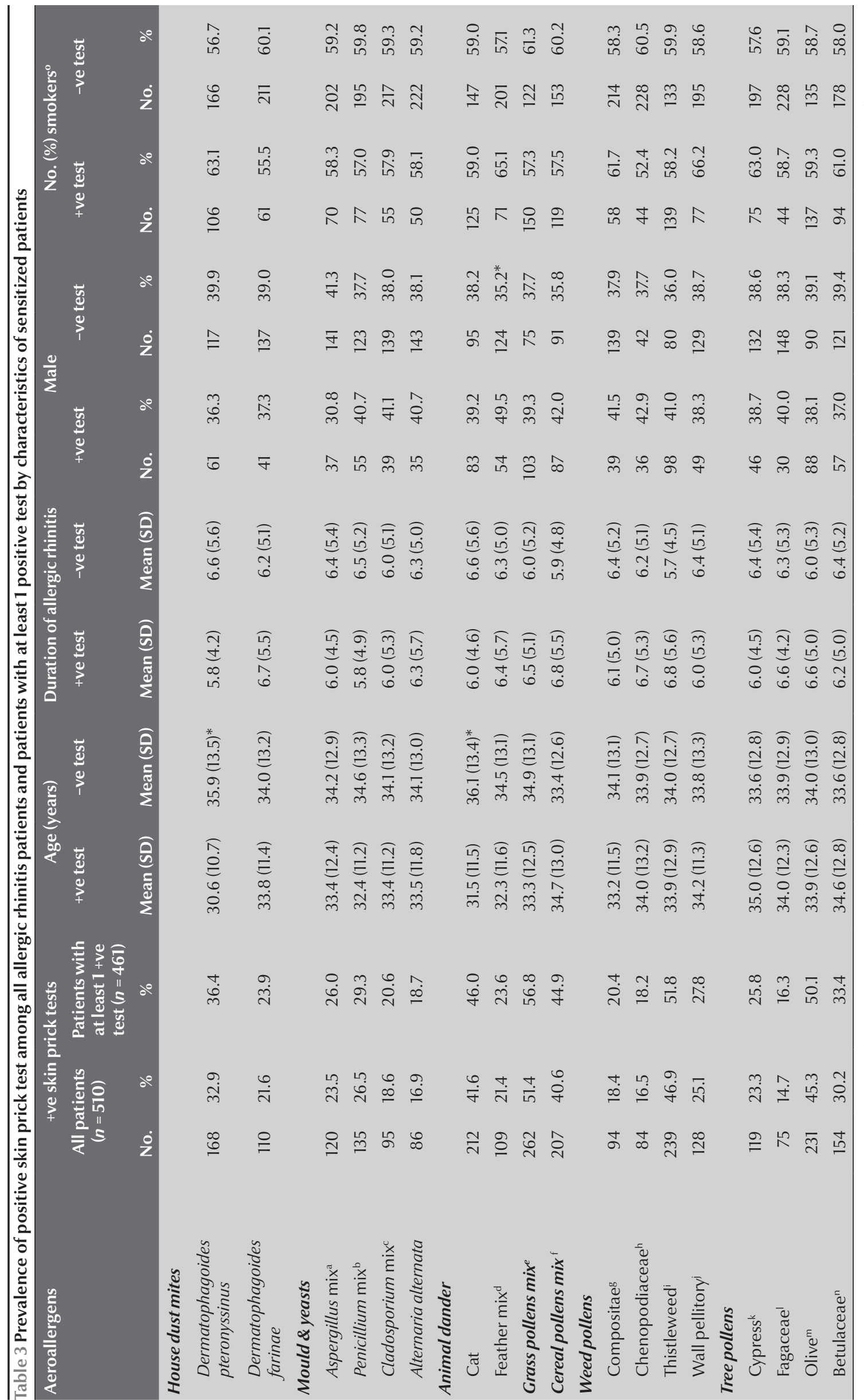




\begin{tabular}{|c|c|c|c|c|c|}
\hline \multirow[t]{2}{*}{ Allergen } & \multicolumn{2}{|c|}{$\begin{array}{l}\text { Intermittent rhinitis } \\
\qquad(n=156)\end{array}$} & \multicolumn{2}{|c|}{$\begin{array}{l}\text { Persistent rhinitis } \\
\quad(n=354)\end{array}$} & \multirow[t]{2}{*}{$\begin{array}{l}P \text {-value for difference } \\
\text { between groups }\end{array}$} \\
\hline & No. & $\%$ & No. & $\%$ & \\
\hline House dust mites & 61 & 39.1 & 151 & 42.7 & 0.45 \\
\hline Moulds \& yeasts & 83 & 53.2 & 176 & 49.7 & 0.47 \\
\hline Animal danders & 70 & 44.9 & 180 & 50.8 & 0.21 \\
\hline Grass pollens & 70 & 44.9 & 192 & 54.2 & 0.05 \\
\hline Cereal pollens & 49 & 31.4 & 158 & 44.6 & $0.005^{*}$ \\
\hline Weed pollens & 90 & 57.7 & 226 & 63.8 & 0.19 \\
\hline \multirow[t]{2}{*}{ Tree pollens } & 92 & 59.0 & 354 & 69.4 & 0.047 \\
\hline & \multicolumn{2}{|c|}{ Mean (SD) } & \multicolumn{2}{|c|}{ Mean (SD) } & \\
\hline $\begin{array}{l}\text { No. of allergens with positive } \\
\text { sensitization }\end{array}$ & \multicolumn{2}{|c|}{$4.3(3.6)$} & \multicolumn{2}{|c|}{$5.3(3.5)$} & $0.003^{*}$ \\
\hline
\end{tabular}

*P<0.006 was selected as the cut-off point for significance because of multiple comparisons.

$S D=$ standard deviation .

are no cats. This is due to the dander being carried on the clothing of people who have cats, then shed in public places. Therefore, cat dander is a component of house dust allergens, even in homes where a cat has never lived $[26,27]$. Cat dander is found in most studies around the world as a major source of allergic sensitization.

When examining the characteristics of patients with positive sensitization we found only a few differences from those with negative sensitization. Patients with positive sensitization to cat dander and to the dust mite Dermatophagoides pteronyssinus were significantly younger than patients who were not sensitized. A similar finding was reported by Broadfield et al, who found that the prevalence of sensitization to a group of allergens (including cat dander and Dermatophagoides pteronyssinus) decreased with increasing age of the patient [28]. Furthermore, sensitization to feathers mix was significantly more prevalent in males than in females. This can be explained by the fact that more males than females in Jordan work in animal farming.

In this study we found that patients with persistent allergic rhinitis had a higher rate of sensitization to seasonal allergens than those with intermittent allergic rhinitis. This finding is supported by another study where patients with monosensitization to olive tree pollens were suffering from allergic symptoms even outside the pollination season [24]. The finding that patients with persistent allergic rhinitis had a higher number of sensitizations than those with intermittent allergic rhinitis possibly contributes to the persistent nature of their disease.

The study was conducted among patients attending ear, nose and throat outpatient clinics and therefore the results may not be representative of the Jordanian population. Another limitation of the current study was that we did not test patients for sensitization toward cockroach allergen which is a recognized perennial allergen. However, only $9(1.8 \%)$ patients reported that they were exposed to cockroaches.

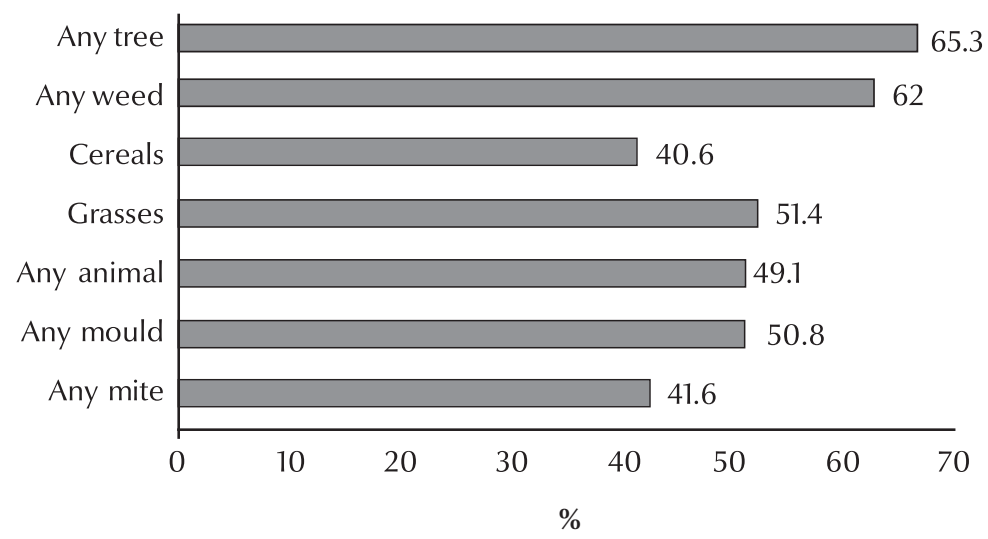

Figure 1 Distribution of positive skin test responses by allergen category 


\section{Conclusions}

Mostallergicrhinitis patientsinthestudy sample suffered from polysensitization. Grasses, olive and thistleweed pollens were the most common allergens in Jordanian allergic rhinitis patients attending outpatient clinics in Amman,
Jordan. Cat dander was the most common perennial allergen. These allergens should be given the highest priority when educating allergic rhinitis patients in Amman regarding allergen avoidance strategies. We recommend that a similar analysis should be conducted in other parts of Jordan.

\section{Acknowledgements}

The authors wish to acknowledge the Deanship of Academic Research at the University of Jordan for funding this research which was part of the protocol entitled "Improving the management of allergic rhinitis in Jordan”.

\section{References}

1. International Rhinitis Management Working Group. International Consensus Report on the diagnosis and management of rhinitis. Allergy, 1994, 49(Suppl.):1-34.

2. Bachert $\mathrm{C}$ et al. Prevalence, classification and perception of allergic and nonallergic rhinitis in Belgium. Allergy, 2006, 61:693-698.

3. The International Study of Asthma and Allergies in Childhood (ISAAC) Steering Committee. Worldwide variation in prevalence of symptoms of asthma, allergic rhinoconjunctivitis, and atopic eczema: ISAAC. Lancet, 1998, 351:1225-1232.

4. Sly RM. Changing prevalence of allergic rhinitis and asthma. Annals of Allergy, Asthma \& Immunology, 1999, 82:233-248.

5. Ciprandi $G$ et al. Quality of life in allergic rhinitis: relationship with clinical, immunological, and functional aspects. Clinical and Experimental Allergy, 2007, 37:1528-1535.

6. Kremer B, den Hartog HM, Jolles J. Relationship between allergic rhinitis, disturbed cognitive functions and psychological well-being. Clinical and Experimental Allergy, 2002, 32:1310-1315.

7. Alvarez-Cuesta E et al. Standards for practical allergen-specific immunotherapy. Allergy, 2006, 61(Suppl. 82):1-20.

8. Bousquet PJ et al. European Community Respiratory Health Survey I. Geographical variation in the prevalence of positive skin tests to environmental aeroallergens in the European Community Respiratory Health Survey I. Allergy, 2007, 62:301-309.

9. Society of Jordanian Chest Physicians. Jordanian pollen calender. Amman, Jordan Medical Association, 2000.

10. Brockow $\mathrm{K}$ et al. General considerations for skin test procedures in the diagnosis of drug hypersensitivity. Allergy, 2002, 57:45-51.

11. Carr WW et al. Immunotherapy Committee of the American Academy of Allergy, Asthma and Immunology. Comparison of test devices for skin prick testing. Journal of Allergy and Clinical Immunology, 2005, 116:341-346.

12. Annesi-Maesano I et al. The score for allergic rhinitis (SFAR): a simple and valid assessment method in population studies. Allergy, 2002, 57:107-114.

13. Bousquet $J$ et al Allergic Rhinitis and its Impact on Asthma (ARIA) 2008 update (in collaboration with the World Health Organization, GA(2)LEN and AllerGen). Allergy, 2008, 63(Suppl. 86):8-160.

14. The European Academy of Allergology and Clinical Immunology. Position paper: allergen standardization and skin tests. Allergy, 1993, 48(Suppl.):48-82.
15. Abdi H. Bonferroni and Šidák corrections for multiple comparisons. In: Salkind NJ, ed. Encyclopedia of measurement and statistics. Thousand Oaks, California, Sage 2007.

16. Fereidouni $M$ et al. Skin prick test reactivity to common aeroallergens among allergic rhinitis patients in Iran. Allergologia et Immunopathologia, 2009, 37:73-79.

17. Ezeamuzie $\mathrm{Cl}$ et al. Asthma in the desert: spectrum of the sensitizing aeroallergens. Allergy, 2000, 55:157-162.

18. Foucard T. Allergy and allergy-like symptoms in 1,050 medical students. Allergy, 1991, 46:20-26.

19. Weber RW. Patterns of pollen cross-allergenicity. Journal of Allergy and Clinical Immunology, 2003, 112:229-239, quiz 240.

20. Suliaman FA et al. Pattern of immediate type hypersensitivity reactions in the Eastern Province, Saudi Arabia. Annals of Allergy, Asthma \& Immunology, 1997, 78:415-418.

21. Lestringant GG et al. A clinical study of airborne allergens in the United Arab Emirates. Allergie et Immunologie, 1999, 31:263-267.

22. Dottorini ML et al. Skin prick-test reactivity to aeroallergens and allergic symptoms in an urban population of central Italy: a longitudinal study. Clinical and Experimental Allergy, 2007, 37:188-196.

23. Güneser $S$ et al. Inhalant allergens: as a cause of respiratory allergy in east Mediterranean area, Turkey. Allergologia et Immunopathologia, 1996, 24:116-119.

24. Kirmaz C et al. Symptoms of the olive pollen allergy: do they really occur only in the pollination season? Journal of Investigational Allergology \& Clinical Immunology, 2005, 15:140-145.

25. Platts-Mills TA et al. The role of intervention in established allergy: avoidance of indoor allergens in the treatment of chronic allergic disease. Journal of Allergy and Clinical Immunology, 2000, 106:787-804.

26. Custovic A et al. Domestic allergens in public places III: house dust mite, cat, dog and cockroach allergens in British hospitals. Clinical and Experimental Allergy, 1998, 28:53-59.

27. Munir AK, Einarsson R, Dreborg SK. Indirect contact with pets can confound the effect of cleaning procedures for reduction of animal allergen levels in house dust. Pediatric Allergy and Immunology, 1994, 5:32-39.

28. Broadfield E et al. Increase in the prevalence of allergen skin sensitization in successive birth cohorts. Journal of Allergy and Clinical Immunology, 2002, 109:969-974. 